\title{
Immunomodulation activity of lectin isolated from Musca domestica (housefly) pupae
}

\author{
Xiaohong Cao \\ Tianjin University of science and technology, Tianjin \\ 300457, China \\ Xiaohongcao2000@yahoo.cn
}

\author{
Chengjian $\mathrm{Xu}$ Binzeng Chunlingwang \\ Tianjin University of science and technology, Tianjin \\ 300457, China \\ Helloxj_2000@yahoo.com.cn
}

\begin{abstract}
As one of important components in traditional Chinese medicines, Musca domestica larvae has been used to cure ecthyma, osteomyelitis, decubital necrosis, malnutritional stagnation and lip boil since the Ming/Qing Danysty. The objective of this study was to evaluate the immunomodulatory effects of the Musca domestica pupae lectin (MPL) on the activity of macrophages and splenocyte. The fraction of buffer insect solution (BIS) lectin was purified by affinity chromatography on galactose-Sepharose-4B and ultrafiltration. This lectin agglutinatin rabbit blood cells $(\mathrm{RBC})$ at $10 \mu \mathrm{g} / \mathrm{ml}$. The immunomodulatory of the MPL was studied by the production of nitric oxide (NO), IL-6 and IL-12 in a dose-dependent manner. The production of IL-6 was induced by MPL at $5 \mu \mathrm{g} / \mathrm{ml}$; IL-12 was significantly induced at $15 \mu \mathrm{g} / \mathrm{ml}$. Lymphocyte transformation test in vitro shown MPL potential as immunomodulator, splenoctye proliferation index was significant increased at $\mathbf{1 0}$ $\mu \mathrm{g} / \mathrm{ml}$ comparing with the control . Our results suggested a portion of the beneficial therapeutic properties of lectin from Musca domestica, our results also supported the concept of using MPL as an immunostimulation adjuvant.
\end{abstract}

Keywords-Musca domestica; Lectin; Immunomodulation
activity; Cytokine

\section{Introduction}

Traditional Chinese medicines use a great variety of insects as drugs, such as Musca domestica. Since the Ming/Qing Danysty the housefly larvae have been used to curev ecthyma, osteomyelitis, decubital necrosis,malnutritional stagnation and lip boil[1]. We investigated Musca domestica in order to find the novel immunomodulator of active substances. Some of the bioactive substances produce beneficial and pharmacological effects, such as lectin purified from Sarcophaga peregrina larvae, which play important role in inducing the INF- $\gamma$ as the lectin incubated with the macrophagus [2]. A novel $40 \mathrm{kDa}$ D-galactose binding lectin was isolated from the flesh fly, which could induce TNF- $\alpha$ in macrophage [3]. However, the lectin of housefly of the agglutination activity and the immunomodulation has not been reported.We have recently purified a pupae D-galactose-binding lectin from Musca domestica (housefly) and this lectin induced macrophage to produce nitric oxide (NO), IL-12, IL-6 and mitogen response on murine splenocytes proliferation.

Our research focus on evaluating the immunomodulatory effects of the purified lectin from Musca domestica (MPL) on the activity of macrophages. Macrophages occupy a unique role in the immune system, in that they can not only trigger innate immune responses but also can be effector cells that contribute to the resolution of these responses[4], such as fighting infection, inflammation, angiogenesis and in the promoting of healing wound. A number of innate system immunomodulators have been isolated from plant and fungi[5], including cytokines[6].The chemical properties and biological activities of lectin have been extensively studied. Some studies have shown that lectins exhibit anti-bacterium[7], and anti-tumor[8], and immunostimulation activities[9]. According to our knowledge, the basic mechanism of the immuno-stimulatory and other immunomodulation effects of Musca domestica pupae's lectin has not reported. Our research is to demonstrate that the immunomodulatory effects of MPL on mice macrophages are associated with nitric oxide, reactive oxygen species, and cytokine releases. Lymphocyte transformation test show MPL is potential immundoulator. Furthermore, modulation of these effects can significantly contribute to humoral and cellular immune responses. We reveal this mechanism of the immunomodulation effects of Musca domestica pupae's lectin.

\section{Materials and methods}

\subsection{Musca domestica and lectin}

The instar larvae of Musca domestica was obtained from Tianjin Disease Prevention and Control Center, Tianjin, China. The larvae were reared until the third instar stage that was injured by inserting the tip of stainless steel needle into the abdominal cavity. The injured insect was then cultivated to become the pupae. The collected pupae was about 30-50 g, which ground and dipped into $200 \mathrm{ml}$ buffer insect solution (BIS) [10] containing $50 \mu \mathrm{g} / \mathrm{ml} \mathrm{N}$-phenylthiourea. The extract was subsequently centrifuged for $20 \mathrm{~min}$ at $10000 \mathrm{rpm}$ to remove the precipitation. Afterwards, the supernatant was concentrated and sterilized by ultrafiltration. Ultrafiltration membranes in different pore sizes were applied to fractionate the supernatant and the main fraction was separated by a membrane with nominal molecular weight cut-off (NMWCO) of $50 \mathrm{kDa}[11]$. Then main fraction was collected and added into $20 \mathrm{ml}$ Sepharose-4B with slow stirring for 1 hour at $4^{\circ} \mathrm{C}$. The mixture was put into $1.5 \times 22 \mathrm{~cm}$ column and washed with $200 \mathrm{ml}$ buffer insect saline with a flow rate of $1 \mathrm{ml} / \mathrm{min}$ until no protein was detected in the elute by monitoring the absorbance at $280 \mathrm{~nm}$. Absorptions were eluted with $0.2 \mathrm{M}$ D-galactose-BIS and fraction was dialyzed extensively against BIS to remove D-galactose[12]. Finally, the lectin was dried under lyophilization and stored in the freezer at $-20^{\circ} \mathrm{C}$ 


\subsection{Haemagglutinating assay of the MPL}

Rabbit blood cells were washed 4 times with $20 \mathrm{mM}$ Tris- $\mathrm{HCl}$ buffer $\mathrm{pH} 7.2$ containing $150 \mathrm{mM} \mathrm{NaCl}$ (TBS) and a final suspension of $2 \%(\mathrm{v} / \mathrm{v})$ was prepared in TBS and treated with pronase $(0.5 \mathrm{mg} / \mathrm{ml})$, incubated at $37^{\circ} \mathrm{C}$ for 1 hour and later washed four times with TBS before use. Hemagglutination tests were performed in standard microtitre plates with v-bottom wells by two fold serial dilution method. The $50 \mu \mathrm{l}$ aliquot of erythrocyte suspension was mixed with $50 \mu \mathrm{l}$ of serially diluted lectin, incubated for $1 \mathrm{~h}$ and visually examined for agglutination. Microscopic observation revealed that co-incubation induced agglutination of blood cells. The unit of activity was expressed as the reciprocal of the highest dilution (titre) of the lectin that showed complete agglutination[13].

\subsection{Inhibition of haemagglutinating assay of the MPL}

To determine the agglutination-inhibition by simple sugars, lectin solution was diluted with different sugar solutions containing $(0.5 \mathrm{mg} / \mathrm{ml})$ sugar in TBS. The lectin in different sugar solutions was incubated with erythrocyte suspension at $37^{\circ} \mathrm{C}$ for $1 \mathrm{~h}$ and then assayed inhibition of haemagglutination [14].

\subsection{Animal}

Male BALB/c mice 6-8 weeks old, 20-25 g weights were housed in open top cages and maintained on food and water. Room temperature was maintained at $22 \pm 2{ }^{\circ} \mathrm{C}$. The light and dark cycle was $14 / 10 \mathrm{~h}$.

\subsection{Isolation of peritoneal macrophages}

Peritoneal fluid from male BALB/c mice were harvested from peritoneal cavities by infusing $10 \mathrm{ml}$ ice-cold sterile PBS (pH7.2-7.4). After centrifugation at 1000rpm for $5 \mathrm{~min}$, the cell pellets were suspended in RPMI-1640 supplemented with $10 \%(\mathrm{v} / \mathrm{v})$ bovine calf serum, penicillin $100 \mathrm{U} / \mathrm{mL}$, and streptomycin $100 \mathrm{U} / \mathrm{mL}$ and seeded in 96-well plate at a cell density of $5 \times 10^{5}$ cells $/ \mathrm{ml}$, and allowed to adhere for $3 \mathrm{~h}$ at $37^{\circ} \mathrm{C}$ in $5 \% \mathrm{CO}_{2}$ humidified incubator. After $3 \mathrm{~h}$ incubation, nonadherent cells were removed by washing twice with PBS and freshly prepared medium was added[15]. The viability of the adherent cells was assessed by trypan blue exclusion test, and the proportion of macrophages was determined by cell morphology under a microscope.

\subsection{Analysis of NO production}

Macrophages were plated at a density of $5 \times 10^{5}$ cells/well in a final volume of $200 \mu \mathrm{l}$ in 96 -well flat-bottom tissue culture plates and incubated in medium alone or medium containing various concentrations of MPL and LPS as a positive control. Cells were incubated at $37{ }^{\circ} \mathrm{C}$ in the presence of $5 \%$ $\mathrm{CO}_{2}$ for $24 \mathrm{~h}$, and $100 \mu \mathrm{l}$ of the cell culture supernatants were removed and analyzed for NO using a colorimetric method with $\mathrm{NaNO}_{2}$ as the standard. Briefly, supernatants were mixed with an equal volume of Griess reagent, which was prepared by mixing one part of $0.1 \% \quad(\mathrm{w} / \mathrm{v}) \quad \mathrm{N}$-(1-naphthyl) ethylenediamine with one part of $1 \%(\mathrm{w} / \mathrm{v})$ sulfanilamide in $5 \%$ phosphoric acid. After 20 min, absorbance was measured at $540 \mathrm{~nm}$ using microplate reader.

\subsection{Determination of IL-12 and IL-6}

Macrophages $\left(5 \times 10^{5}\right.$ cells $\left./ \mathrm{ml}\right)$ were cultured in the presence of various concentrations of MPL in a 96-well plate in a total volume of $100 \mu \mathrm{l}$ up to $48 \mathrm{~h}$, or cultured for different time in the presence of MPL $(25 \mu \mathrm{g} / \mathrm{ml})$. Productions of IL-6 and IL-12 were measured using enzyme-linked immunosorbent assay (ELISA) kits.

\subsection{Lymphocyte transformation test}

A single cell suspension of spleen was prepared from the $\mathrm{BALB} / \mathrm{c}$ mice under aseptic conditions by homogenization in Hank's balanced salt solution (HBSS). The suspension was centrifuged to obtain cell pellet. The contaminated red blood cells were then removed by hemolytic Gey's solution. After two washes in HBSS, the cells were resuspended in complete RPMI. Cell concentration was adjusted to $1 \times 10^{6}$ cells $/ \mathrm{ml}$ and viability of splenocytes (tested by trypan blue dye exclusion) was always over $90 \%$. Subsequently, the cells $(180 \mu \mathrm{l})$ were plated in 96 well flat bottom plates and incubated with $20 \mu \mathrm{l}$ of various concentrations $(5 \mu \mathrm{g}-50 \mu \mathrm{g} / \mathrm{ml})$ of MPL. The positive controls incubated with $20 \mu \mathrm{l}$ ConA $(5 \mu \mathrm{g} / \mathrm{ml})$. All cultures were performed in triplicate for $72 \mathrm{~h}$ at $37^{\circ} \mathrm{C}$ in a humidified atmosphere of $5 \% \mathrm{CO}_{2}$. The proliferative response of lymphocyte was measured by the MTT method [16].

\subsection{Statistical analysis}

Results were expressed as mean \pm standard deviations (S.D.). Data were analyzed using Analysis of Variance (SAS 8.0) and T-test to consider the statistical significance $(\mathrm{P} \leq 0.01)$.

\section{Results}

\subsection{Isolation of the lectin from Musca} domestica pupae

Affinity chromatography by using Sepharose-4B was able to absorb lectin effectively from housefly haemolymph. All the proteins without $\mathrm{D}$-galactose specific character were eluted out from the column rapidly. The fractions eluted with $0.2 \mathrm{M}$ D-galactose in BIS as the arrow indicated showed an obvious haemagglutinating activity (Fig. 1)

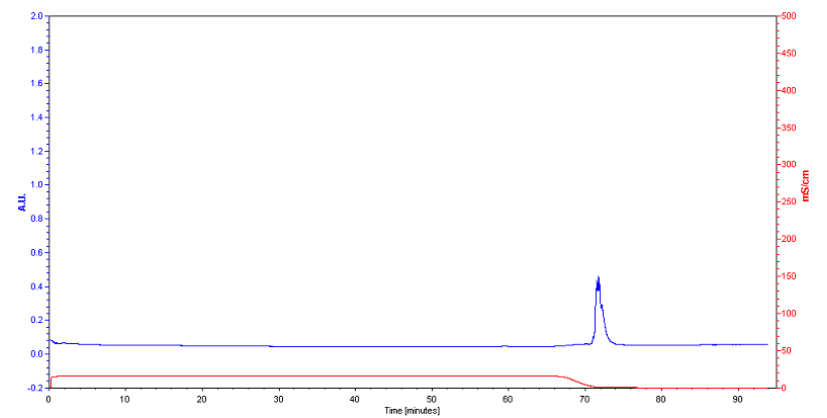

Fig 1 Affinity chromatography of lectin from Musca domestica pupae. Immune pupal hemolymph was applied to a Sepharose-4B column and eluted with $0.2 \mathrm{M}$ D-galactose in buffered insect saline as the arrow indicated in $70 \mathrm{~min}$. Proteins corresponding to the peak yield at about $73 \mathrm{~min}$ showed a significant haemagglutinating activity.

\subsection{Hemagglutination activity of MPL}

Agglutinin in the lectin agglutinated red blood cells from human, rat and rabbit with high titers(the date not show).The 
minimum protein required for agglutination RBC's were 2 $\mu \mathrm{g} / \mathrm{ml}$. In this study, the MPL at $20 \mu \mathrm{g} / \mathrm{ml}$ showed more hemagglutination activity than that at $10 \mu \mathrm{g} / \mathrm{ml}$ concentration (Fig 2).

\subsection{Inhibition of haemagglutinating activity}

A variety of carbohydrates were used to detect the carbohydrate-specific character of MPL. Total inhibition was observed when D-galactose was used and the hemagglutination activity decreased with time(Fig 2D).

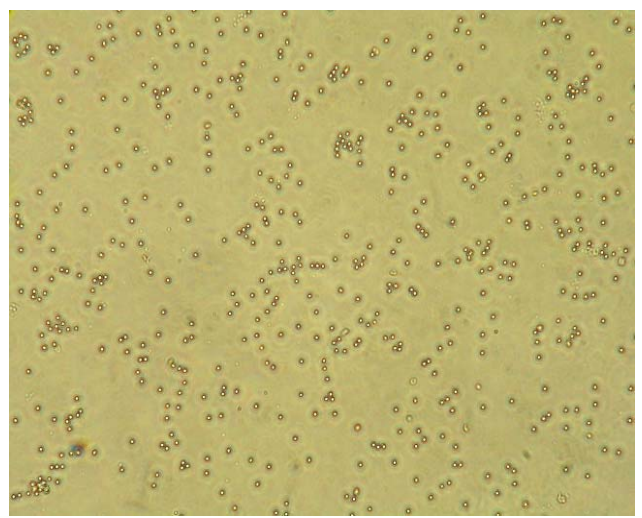

A

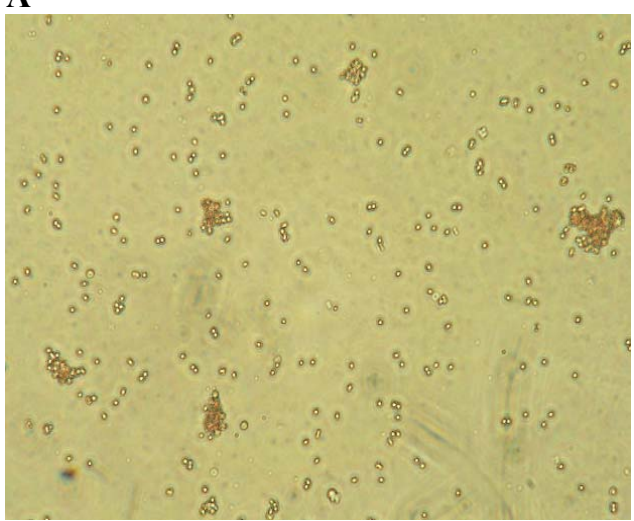

B

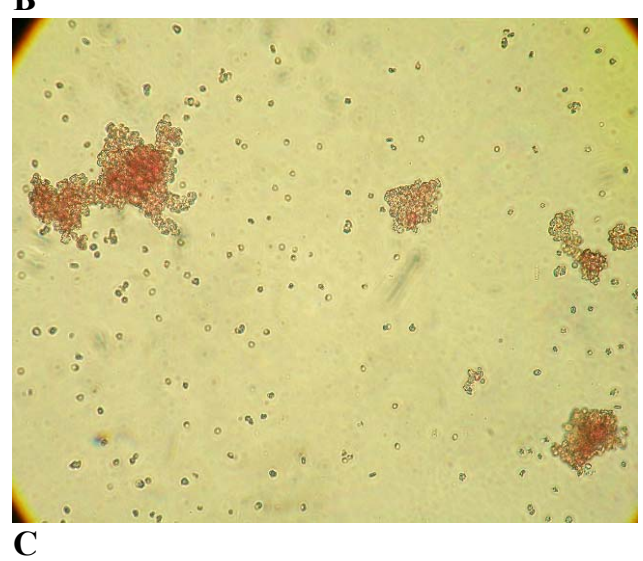

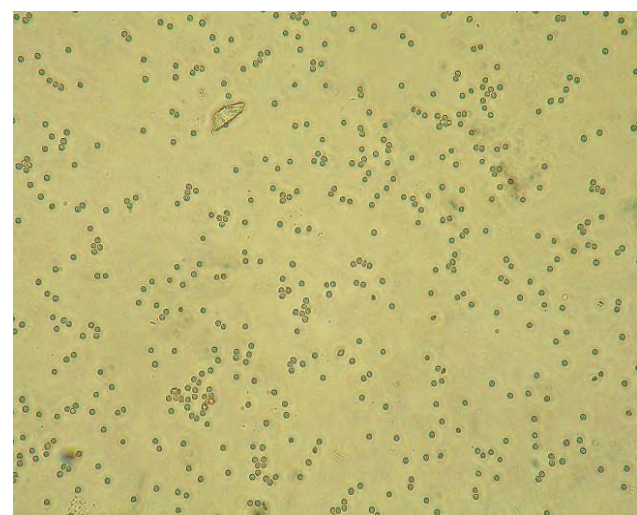

D

Fig 2 Agglutination of rabbit blood cell

A) Control rabbit blood cell plus TBS buffer $(2 \% \mathrm{v} / \mathrm{v})$. (B) rabbit blood cell incubating with $10 \mu \mathrm{g} / \mathrm{ml}$ of MPL. (C) rabbit blood cell incubating with $20 \mu \mathrm{g} / \mathrm{ml}$ of MPL. (D) rabbit blood cell plus $10 \mu \mathrm{g} / \mathrm{ml}$ of MPL and $25 \mu \mathrm{l}$ of $0.5 \mathrm{mg} / \mathrm{ml} \mathrm{D}$-galactose. Magnification: 20x.

\subsection{Effect of MPL on macrophage NO}

A minimum amount of NO was produced when murine peritoneal macrophages were incubated with medium alone; whereas, treatment of these cells with the MPL resulted in a concentration-dependent increase in NO production (Fig. 3A), NO production induced by MPL at $50 \mu \mathrm{g} / \mathrm{ml}$ was comparable to the control $(0 \mu \mathrm{g} / \mathrm{ml}$ of MPL). The positive was the LPS(2 $\mu \mathrm{g} / \mathrm{ml}$ ) .To further investigate whether the production of NO by MPL was time-dependent, macrophages were cultured for $0-48 \mathrm{~h}$ at a concentration of $25 \mu \mathrm{g} / \mathrm{ml}$ MPL. As shown in (Fig. 3B), A time-dependent enhancement of NO production was observed in macrophages treated for $0-48 \mathrm{~h}$.

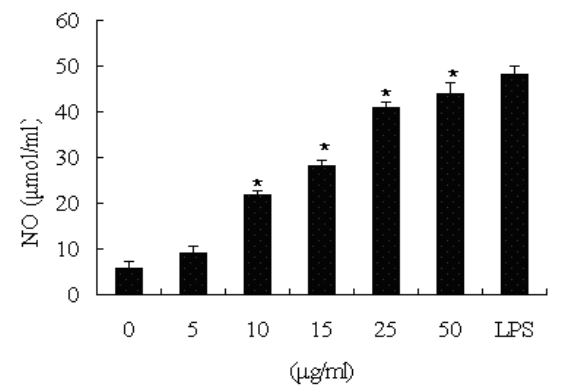

$\mathbf{A}$

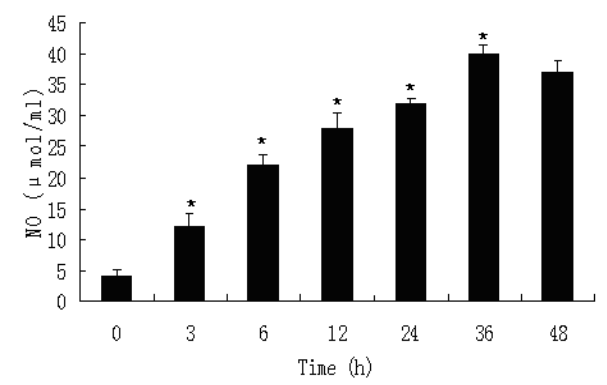

$\mathrm{B}$

Fig 3 Effects of MPL on the production of NO by peritoneal macrophages in vitro. (A) Macrophages of mice was 
stimulatedwith MPL $(0-50 \mu \mathrm{g} / \mathrm{mL})$ or LPS $(2 \mu \mathrm{g} / \mathrm{mL})$ for $48 \mathrm{~h}$. (B) Peritoneal macrophages were incubated with MPL $(25 \mu \mathrm{g} / \mathrm{mL})$ for $0-48 \mathrm{~h}$. Each value represents the mean \pm S.D., $(\mathrm{n}=4) . * \mathrm{P} \leq 0.01$ vs control.

3.6 Effect of MPL on macrophage IL-6 and IL-12 production

A number of immunomodulatory compounds can upregulate cytokine production. We also analyzed the effects of MPL on macrophage IL-12 and IL-6 production. A minimum amount of NO was released when macrophages were exposed to medium alone, whereas incubation of these cells with the MPL significantly enhanced IL-6 and IL-12 production in a does-dependent manner (Fig. 4A and 5A). These responses were quite robust, and the levels of IL- 6 induced by 5-50 $\mu \mathrm{g} / \mathrm{ml}$ of MPL were comparable to the control $(0 \mu \mathrm{g} / \mathrm{ml}$ of MPL ) in mice macrophages. Interestingly, MPL-activated macrophages produced amount of IL-6, which reaching approximately $420 \mathrm{pg} / \mathrm{ml}$ at $50 \mu \mathrm{g} / \mathrm{ml}$ of MPL. This effect of MPL was more than that of LPS. Furthermore, a time-dependent enhancement of IL- 6 and IL-12 production was also observed in macrophages treated for $0-48 \mathrm{~h}$ (Fig. 4B and 5B).

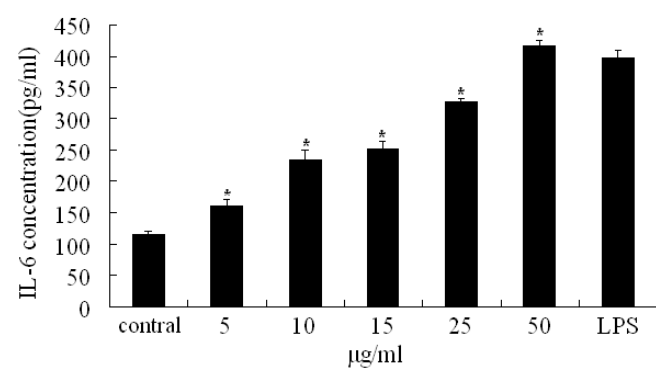

A

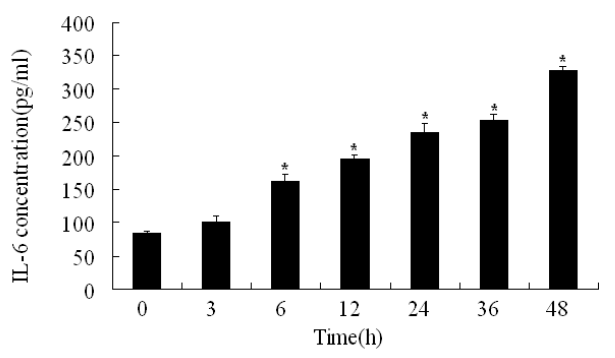

B

Fig 4 Peritoneal macrophages of male BALB/c mice were incubated with the indicated concentrations of the lectin. (A)Peritoneal macrophages were treated with LPS $(2 \mu \mathrm{g} / \mathrm{ml})$ or MPL for 48h.( B) Macrophages were cultured in 96-well flat-bottomed plate with or without MPL $(25 \mu \mathrm{g} / \mathrm{ml})$ for $0-48 \mathrm{~h}$. Culture media were analyzed for IL-6 by ELISA kit. Each value represents the mean \pm S.D., $(n=4)$. $* \mathrm{P} \leq 0.01$ vs control.

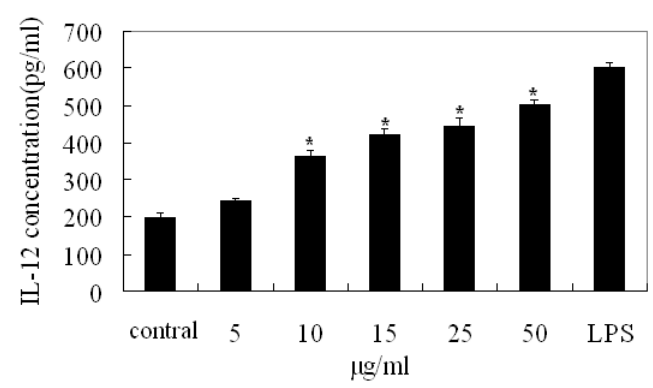

A

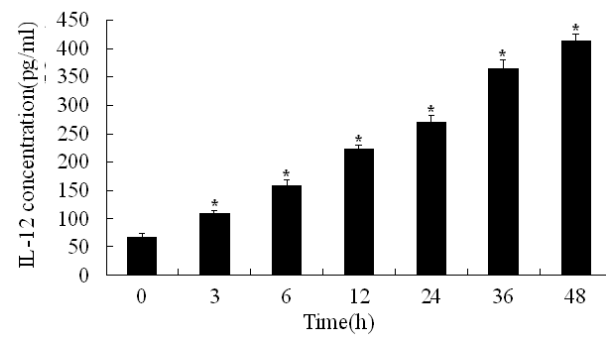

B

Fig 5 Effects of MPL on IL-12 secretion at different concentration of mice macrophages in vitro. (A) Peritoneal macrophages were treated with MPL or LPS $(2 \mu \mathrm{g} / \mathrm{ml})$ for 48 h. (B) Macrophages were isolated from BALB/c mice and cultured in 96-well flat-bottomed plate with or without MPL (25 $\mu \mathrm{g} / \mathrm{ml}$ ) for $0-48 \mathrm{~h}$. Culture media were analyzed for IL-12 by a ELISA kit. Each value represents the mean \pm S.D., $(n=4)$. $* \mathrm{P} \leq 0.01$ vs. control.

\subsection{Splenocyte proliferation by MPL with and without of the carbohydrate ligand D-galactose}

To ensure MPL induced splenocyte proliferations was dependent upon interaction with carbohydrate-associated structure on immune cells, the soluble sugar ligand D-galactose was assayed for inhibiting the splenoycte proliferation properties. Spleen cell suspensions were incubated with $20 \mathrm{mM}$ D-galactose and these were stimulated with different concentrations of MPL, As shown Fig. 6, MPL specific carbohydrate ligand D-galactose inhibited MPL induced splenocyte proliferation in low MPL concentration, while in low concentration unaffecting the response to MPL. This indicated that MPL did interact with cells through the carbohydrate binding pockets for immune stimulation. We compare the SPI data of MPL with or without D-galactose Fig.6B. We observed that SPI in a dose-dependentmanner without D-galactose and SPI with D-galactose were not significantly increased. The lectin stimulated splenocyte proliferation, while in present of D-galactose this lectin was inhibited mitogenic stimulation[17].

\section{Discussion}

Bioactive proteins such as lectins have been isolated from plant, invertebrate and insect, especially those with specificity to monosaccharides D-galactose and D-mannose[18]. Some lectin used to purify by carbohydrate which inhibited haemagglutinating ativity of lectin[19]. In the present work we 
have purified a lectin from Musca domestica, the lectin of Musca domestica activity in the hemolymph was specific bound by D-galactose, so we purified this protein by affinity chromatography on Sepharose-4B, which consists of the galactose polymer. Lectin was eluted with $0.2 \mathrm{M}$ D-galactose from affinity column. We collected the main fraction and then taken for assay of haemagglutinating activity. Lectins are proteins that recognize specific carbohydrates[20], which haemagglutinating activity was inhibited by some monosaccharides. Purified lectin was tested for their ability to agglutinate the RBC. Microscopic observation revealed that co-incubation induced agglutination of blood cells (Fig. 2B). Reduction in blood cells agglutination was observed when lectin was pre-incubated with D-galactose. The blood cells agglutination might be due to the presence of cognate glycan on the cell surface. The agglutination activity inhibited by D-galactose via pre-incubated with D-galactose(Fig. 2D).
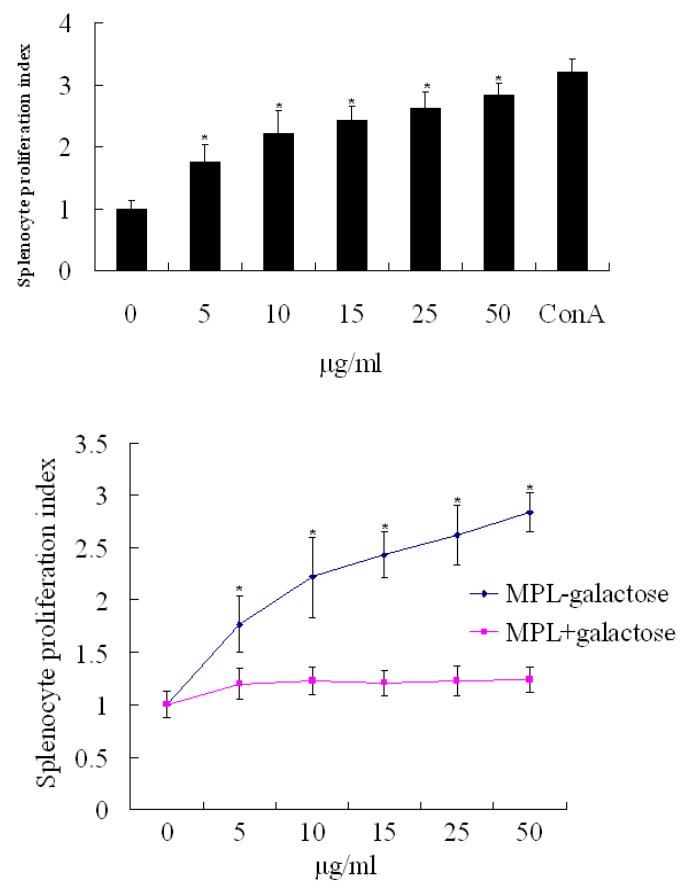

B

Fig 6 Splenocyte proliferation by MPL. (A)Murine splenocytes $\left(10^{6}\right.$ cells $\left./ \mathrm{ml}\right)$ were stimulated by MPL $(5-50 \mu \mathrm{g} / \mathrm{ml})$, Con A $(5$ $\mu \mathrm{g} / \mathrm{ml}$ ) for $72 \mathrm{~h}$ at $37^{\circ} \mathrm{C}$ in a humidified atmosphere of $5 \% \mathrm{CO}_{2}$. (B) Murine splenocytes (106 cells $/ \mathrm{ml}$ ) were stimulated by MPL $(5-50 \mu \mathrm{g} / \mathrm{ml})$ with or without D-galactose. Increase in cell number was measured by MTT assay method. Each value represents the mean \pm S.D., $(\mathrm{n}=6)$. ${ }^{*} \mathrm{P} \leq 0.01$ vs control.

Macrophages play critical roles in host defense, including phagocytosis of pathogens and apoptotic cells, production of cytokines, proteolytic processing and presentation of foreign antigens [21,22]. Thus, the bioactive substances that can modulate macrophages are of significant interest. Indeed, a variety of lectins have been reported to exhibit beneficial pharmacological effects via their ability to modulate macrophage function[23,24]. IL-6 is regarded as a major immune and inflammatory mediator. IL-12 produced by macrophages enhances $T$-cell responsiveness[25]. In this study, this lectin contained potent macrophage immunomodulation activity, as demonstrated by induction of effector molecules, such as NO, cytokines . In addition, treatment with MPL resulted in a significantly enhance response, which is indicative of a trigger effect. MPL was shown to induce macrophages to produce IL-6 and IL-12 in a dose- and timedependent manner.

Mitogenic lectins utilize the capacity of protein-carbohydrate interaction and glycan cross linking to stimulate immune parameters; the degree of immune response depends on affinity of lectin to cell surface glycans of receptors and co-receptors. But there are evidences as well as speculations in favor of non-carbohydrate lectin interaction with cell surface molecules[26,27]. Lectin induced mitogenic response is associated with production and secretion of NO and cytokines (IL-1, IL-6, IL-10, IL-12, TNF $\alpha$, GMCSF) [28,29]. Musca domestica pupae lectin belongs to lectin which utilized the capacity of protein- carbohydrate interaction and glycan cross linking to red blood cells (Fig 2C). In the present study that MPL induced to produce NO from macrophages, which has been show the principal effector molecule for cytotoxic activity. NO can be used as a quantitative index of macrophage activation [21]. NO is related to cytolytic function of macrophages against a variety of tumors[22]. The experimental data suggested similar properties shown by LPS that stimulates NO production by macrophages. The non-activated macrophages produce very low amount of NO.

All the functional properties of lectins in vitro are strongly inhibited by corresponding ligand carbohydrates[30,18]. Further experimental data suggested that MPL was able to stimulate mice splenocytes for proliferation though the proliferation index was much less than that of ConA (Fig 3). However, it was found in case of mice lymphocytes were stimulated by MPL in presence of D-galactose, splenocytes proliferation index has not significant change. This result suggested that carbohydrate recognition domain is necessary for MPL mediated bioactivity.

In conclusion, this is the first study on the effect of lectin from the Musca domestica on mice peritoneal macrophages giving new insights into the action of MPL. MPL activate macrophages, resulting in modulation of NO and cytokine production. The experimental data suggested MPL induced splenocyte proliferations with dose-dependentmanner. Further studies are in progress to determine which receptor(s) are essential to the expression of the various immunomodulatory effects ascribed to MPL and signaling cascades resulting in immunomodulatory effects. 


\section{Reference}

1. S.J.Jiang, 1999. Chinese Pharmaceutical Insects (in Chinese). Chinese Forestry Publishing House, Beijing, China.

2. M .Tamura, S. Natori., 1984, Induction of human $\gamma$ interferon by sarcophagi peregrina humoral lectin, FEBS 175, 325-327.

3. A. Itoh, K.Iizuka, S.Natori, 1984. Induction of TNF-like factor by murine macrophage-like cell line J774.1 on treatment with Sarcophaga lectin, FEBS letters, 175,59-62

4. M. Ballow , R. Nelson, 1997. Immunopharmacology: immunomodulation and immunotherapy. Jorunal of the American medical Association, 278, 8-17.

5. S. Tripathi, , K. Tapas., H. Maiti, 2005. Immunomodulatory role of native and heat denatured agglutinin from Abrus precatorius. The International Journal of Biochemistry \& Cell Biology 37, 451-462.

6. F. Villinger, 2003. Cytokines as clinical adjuvants: how far are we? Expert Review of Vaccines, 23,17-26.

7. M. Nagaraj, U. Gowda , M. Goswami, K. Islam, 2008. T-antigen binding lectin with antibacterial activity from marine invertebrate, sea cucumber (Holothuria scabra): Possible involvement in differential recognition of bacteria, Journal of Invertebrate Pathology 99, 141-145.

8. S. A.Cesar , A. Maria, T. S. Correia, B. B. C. Luana., C. Silene, 2004, Antitumor activity of Cratylia mollis lectin encapsulated into liposomes, International Journal of Pharmaceutics 278:435-433

9. H. K. Patric , T. B.Ngai , 2004. A mushroom (Ganoderma capense) lectin with spectacular thermostability, potent mitogenic activity on splenocytes and antiproliferative activity toward tumor cells, Biochemical and Biophysical Research Communications, 314, 988-993.

10. H. Komano, 1980. Purification of lectin induced in hemolyph of Sarcophaga peregrina larvae on injury. The Journal of Biological Chemistry, 255, 2919-2924.

11. J.C. Sheng, F. Yu, Z.H. Xin, L.Y. Zhao, 2007, Preparation Identification and Their Antitumor Activities in vitro of Polysaccharides from Chlorella Pyrenoidosa. Food Chemistry 105, 533-539.

12. X. H. Cao, Y. CHen, Y. Zhang, 2003. Isolation and Characterization of Musca domestic pupae Lectin(in Chinese). Progress in Biochemistry and Biophysics 30, 442-446.

13. W. S. Fisher, A. R. Dinuzzo, 1991. Agglutination of bacteria and erythrocytes by erum from six species of marine molluscs. Journal of Invertebrate Pathology 57,380-394.

14. S. Jayasree, 2001. Biological properties of a natural agglutinin in the hemolymph of Indian white prawn, Penaeus indicus H. Milne Edwards, Aquaculture, 194, 245-252.

15. M. P. Mariana, D.F. Buchi, A.J. Gorin Philip , I. Marcello , O. M. Benigna , 2003. Effect of an acidic heteropolysaccharide (ARAGAL) from the gum of Anadenanthera colubrina (Angico branco) on peritoneal macrophage functions. Immunology Letters, 89,175-85.

16. Mossman, T et al., 1983. Rapid colorimetric assay for cellular growth and survival: Application to proliferation and cytotoxicity assays. Journal of Immunological Methods, 65, 55-63.
17. S. Tripathi, K. Tapas, H. Maiti, 2005. Immunomodulatory role of native and heat denatured agglutinin from Abrus precatorius. Int. J. Biochem. Cell. Biol. 37: 451-462.

18. N. M. N.Alencar, M. S. Assreuy Ana, V. B. M. Alencar, S. C.Melo, M. V. Ramos, B. S.Cavada, 2003. The galactosebinding lectin from Vatairea macrocarpa seeds induces in vivo neutrophil migration by indirect mechanism. The International Journal of Biochemistry \& Cell Biology 35, $1674-1681$.

19. S.G. De-Simone, C. C. Netto, F. P. Silva Jr, 2006. Simple affinity chromatographic procedure to purify $\beta$-galactoside binding lectins, Journal of Chromatography B 838: 135-138

20. T. Fujita, 2002. Evolution of the lectin-complement pathway and its role in innate immunity, Nature Reviews Immunology 346-353.

21. R. B. Lorsbach, W. J. Murphy, C.J. Lowenstein, S.H. Snyder, S. W. ussell, 1993. Expression of the nitric oxide synthase gene in mouse macrophages activated for tumor cell killing. Molecular basis for the synergy between interferon-gamma and lipopolysaccharide. Journal of Biological Chemistry, 268,1908-1913.

22. J. B. Hibbs, R. R.Taintor, Z. Vavrin, 1987. Macrophage cytotoxicity: role for L-arginine deiminase and imino nitrogen oxidation to nitrite. Science 235:473-479.

23 M. Takei, H. Nakagawa, 2006. A sea urchin lectin, SUL-1, from the Toxopneustid sea urchin induces DC maturation from human monocyte and drives Th1 polarization in vitro. Toxicology and Applied Pharmacology 213, 27-36

24. H. X. Wang, T. B. Ng, Q. H. Liu, 2002. Isolation of a new heterodimeric lectin with mitogenic activity from fruiting bodies of the mushroom Agrocybe cylindracea. Life Sciences 70,877-885

25 J. Y. Song, S. K. Han, E. H. Son, S.K. Pyo , Y. S.Yun, S.Y. Yi , 2002. Induction of secretory and tumoricidal activities in peritoneal macrophages by ginsan. Int Immunopharmacology 28,57-65.

26. H. J. Gabius, 1994. Mini review. Non-carbohydrate binding partners/domains of animal lectins. International Journal of Biochemistry, 26:469-477.

27. K. R.Oldenburg, D.Loganathan, I. J.Goldstein, P. G. Shultz, M. A. Gallop, 1992. Peptide ligands for a sugar-binding protein isolated from a random peptide library. Proceedings of the National Academy of Science of the United States of America 89,5393-5397.

28. H.J.Gabius, 2001, Probing the cons and pros of lectin-induced immunomodulation: Case studies for the mistletoe lectin and galectin-1. Biochimie 83,659-666.

29. T. Barbosa, S. S'ergio Arruda, B. Cavada, T. B. Barbosa, R. A. L.Freitas, B. M. Netto, 2001. In vivo lymphocyte activation and apoptosis by lectins of diocleinae subtribe. Mem Inst Oswaldo Cruz, Rio de Janeiro 96, 673-678.

30. O.Closs , E. Saltvedt, S. Olsnes, 1975. Stimulation of human lymphocytes by galactose-specific Abrus and Ricinus lectins. Journal of Immunology $115,1045-1048$ 